\title{
10
}

\section{Use of information technology to address institutional failure}

\author{
Asim Barman
}

This chapter describes the experience of deploying information technology (IT) in Calcutta Municipal Corporation to arrest corruption in the municipal administration of Calcutta, a bustling metropolis in India. In the face of apparently insurmountable problems, IT was used as a means of institutional strengthening in the public sector organisation. Introduction of IT in Calcutta Municipal Corporation has had many benefits, including fast and accurate flow of information, increased revenue generation, decentralised planning, effective operational control, a paperless environment, and strengthening of both intra-organisational and interorganisational communication systems.

The chapter specifically focuses on how the introduction of IT checked corruption, and helped improve efficiency and effectiveness in dealing with

- property tax assessment and collection

- expenditure management

- solid waste management.

The Calcutta Metropolitan Area is 1,380 square kilometres in area, and has a population of about 12 million (about 59 per cent of the urban population of West Bengal). It has three municipal corporations (Calcutta, Howrah and Chandannagar), 35 municipalities, three notified areas, and 540 rural units. The city of Calcutta itself is 187 square kilometres in area, with a population of 4.38 million (at night), which increases by 2 million floating population during the day. With an average population density of 23,381 persons per square kilometre, there is tremendous pressure on land as well as civic services and amenities available for residents in the city. Calcutta Municipal Corporation's area of jurisdiction and population offer many challenges in providing efficient and effective municipal services across the city limits. 
The Calcutta Municipal Act 1951 came into effect on 1 May 1952. It was revised in 1980, and the subsequent Act came into force on 4 January 1984. Under the Municipal Act, the Calcutta Municipal Corporation is the principal agency responsible for water supply, sewerage and drainage/ water disposal facilities in the urban metropolis of Greater Calcutta. The Corporation's major service sectors include

- solid waste management

- health

- water

- sewerage

- roads

- trade licences

- property records maintenance.

\section{The context}

A new global information economy based on knowledge and intellectual capital is fast replacing the industrial economy of today. The global marketplace and its technological infrastructure reflect shifts from manufacturing and distributing physical products to the development of products that are differentiated only by the information that is contained within them. Indeed, the information is often itself the product. Further, these information products are delivered through a combination of advanced digital networks that cannot be contained within geographic borders.

Like industries, many governments are engaged in internal reengineering of their activities so as to improve efficiency through use of technology and to deliver government services electronically to citizens. Economic benefits accruing to governments from technological integration have historically been viewed in terms of cost savings and returns on investments from specific projects. However, in a rapidly expanding information-based economy, governments must deal with a complex set of issues including regulation, deregulation, unbundling, licensing, incentives, and risk management among service providers. The successful governance of cities and urban areas requires both sophisticated IT strategies and institutional reforms in government organisations, based on fundamental rethinking of associated public policy.

In India, it was only during the Eighth Five-year Plan (1992-97) that some state governments initiated a program of institutional reforms in the urban planning, water supply and sewerage sectors. These were through

- imparting a commercial orientation to the sector

- exposing the sector to market forces through encouragement of private participation 
- financing projects in the sector through a well-developed secondary debt market

- consolidation of gains already achieved in creating the best possible regulatory framework

- introduction of information technology to aid governance.

This chapter examines the introduction of IT in Calcutta Municipal Corporation beginning in 1994-95, and the effects it has had in streamlining the Corporation's dealings with the citizens. Information technology became the crucial lever for dramatic change. 'Lead us from captivity to freedom, from darkness to light and from despair to hope' was how the role of IT was envisaged when the change began. Calcutta Municipal Corporation was captive because it could not share its information with citizens of the metropolis. Its staff was captive because they had no access to information about the outside world. Citizens were in the dark about the Corporation's functions, as they had no access to information about the Corporation. Taxpayers and others directly or indirectly associated with the Corporation did not know what was in store for them, due to the Corporation's poor data and knowledge bank. In the pre-IT scenario the effectiveness and efficiency of any organisation depended, among many other factors, on the quality of personnel it possessed. In other words, human resources used to be the biggest asset to a vast organisation like Calcutta Municipal Corporation where the establishment cost, inclusive of wage bill, was more than the development cost.

Unfortunately, for various reasons, Calcutta Municipal Corporation had been deprived over the years of the services of the best talents available in the market. As a result, the Corporation was overstaffed and generally underskilled. In the absence of new recruitment at middle management level or lateral transfers in the Corporation's services, supervision, monitoring and evaluation of programs were poor. This was primarily because creativity and innovation could not be expected from the people who had risen from the ranks and also because they were not respected by their juniors. Consequently, municipal services suffered from poor supervision and management skills.

Calcutta Municipal Corporation's databank was very weak. The citizens at times fell prey to the unscrupulous elements of the organization. Manipulation of data, and distortion of information, exploitation and extortion of the citizens in general, were common. Consequently, the negative image of the city was firmly anchored in the minds of both the citizens and the outside world. This negative image emboldened the Corporation's staff to engage in corrupt practices. Institutional failure thus propagated varying degrees of corruption. 
The primary task for top management in the mid 1990s was to address this institutional failure. It was not possible to replace existing staff, within the existing framework of the staff policy, with quality personnel. Nor was it desirable to create many new posts and recruit quality staff in addition to the existing employees. Therefore, the only remaining option was to introduce information technology into the Corporation in a phased manner.

In introducing information technology in Calcutta Municipal Corporation, political factors had to be kept in mind. Calcutta was a centre of opposition and protest during the age of automation of the early 1970s. The state government lead by Leftist parties was initially not favourably inclined towards automation. The employees of the state government, including the staff of Calcutta Municipal Corporation, feared job losses with the advent of automation.

\section{Information technology implementation-three case studies}

Information technology was progressively introduced in 1994-95 in Calcutta Municipal Corporation's three key areas of operations-property tax assessment and collection, expenditure management, and solid waste management.

\section{Case 1 Property tax assessment and collection}

The main areas of revenue generation within Calcutta Municipal Corporation are its Property Tax Assessment and Collection and Property Mutation Services. Under these, major activities undertaken include

\section{Annual tax billing}

From 1993-94 to 1999-2000, the Corporation's assessee base for property taxation grew from 350,000 to 400,000 households. Consolidated annual tax bills for assessees owning property in their name are payable in four instalments (one bill for each quarter) for each financial year. These bills are based on an annual valuation made by the Corporation for each assessee through a standard legal assessment procedure.

\section{The need for automation}

There were many reasons for automating this service.

- The volume of bills is huge-ensuring they are correct using manual methods is nearly impossible. Currently, consolidated tax bills are computerised and mailed under certified post from 
the data processing department. If an assessee claims that they have not received the tax bill, an information database can be accessed to verify the complaint and a duplicate tax bill can be generated at the counter.

- Corruption inherent in the system had led to tampering of data in case of high valued property. Previously, discrepancies could be noted only at the time of general revaluation after every six years. By automating the business process of the hearing system, the immunity of the annual valuation is ensured.

- If the tax bill cannot be served, the assessee cannot be declared in default even if the due date of payment lapses. Therefore, the mailing address is vital to ensure that the collection is proper and the Corporation's revenue claims are valid.

- To ensure functionality, the areas under the Corporation are marked as wards. A ward has a number of streets under its jurisdiction; a street has a number of premises; and a premise can have a number of assessees (for example, multi-storied buildings). Identification of assessment backlogs are impossible manually but are successfully handled using IT.

- Once the bill is generated successfully, the problem shifts to collection and reconciliation of payments. Manual procedures produce huge gaps, which result in improper updating of assessee's records. Also, Calcutta Municipal Corporation can never ascertain the defaulter list. The Corporation has around 18 consolidated tax collection centres where the counterfoils of the bills are retained, on the basis of which manual summary information and computerised information summaries are tallied. The Corporation's counter clerks often receive a tax with rebate even after the rebate date has lapsed, leading to loss of revenue. This bottleneck has been removed by using collection software at the counters. It has also assisted in reconciliation of the non-realisation of payment made by cheques by providing receipts only after the cheque has been cleared.

\section{Introducing automation}

A system of progressive automation was incorporated in the following areas.

- Present demand bills. Previously, present demand bills were printed quarterly and mailed separately. In cases where the bill did not reach a person on time, was lost, or not paid on time, the person had to come to the Corporation's head office to get the bill details or to have the penalty interest calculated 
manually. The computerisation of present demand bills has resulted in one-time printing and mailing of the bills for all quarters, thereby reducing expenses. Reprinting of bill and interest calculation has also been automated and has reduced corrupt practices. Taxpayers' addresses are kept on file, hence reducing the chances of the bill being lost. Accurate reconciliation of the payment due and the amounts received is also possible.

- Supplementary bills. Previously, re-evaluation of property was manual and subsequent applications from the taxpayer and the hearings were supervised by local councilors. This generated a lot of corrupt practices. The system has now been automated and the assessee numbers are being generated by the system, which means that re-evaluation can be done accurately and on time.

- Fresh bills. New assessees register with Calcutta Municipal Corporation after mutation and the fresh bill is raised to calculate the amount due between date of registration and the next financial year.

\section{Streamlining the hearing system}

The hearing system was also streamlined in the following ways.

- A proposed annual valuation is intimated to each assessee for general or intermediate revaluation through hearing notice. In the manual system, the assessee was often never informed and the backlog cases therefore used to rise. The annual variation proposed in the intimation was not known to the assessee, and he was thus trapped in a situation where a higher annual variation could be intimated to him, which he was required to pay unless he went in for a deal that also involved a corrupt practice.

- On completion of the hearing, the assessee received a rate card in which the confirmed annual valuation was written along with the surcharge (if any). There were no controls on the number of adjournments provided to an assessee or the gap in the hearing dates, which resulted in a lengthy hearing cycle. There was also no control on the number of cases heard, number of adjournments, or the number of hearings done.

- If the annual valuation for any completed general or intermediate revaluation quarter is fixed on a subsequent quarter, then the difference of taxes between the previously 
fixed annual valuation and the newly fixed annual valuation is collected through a supplementary bill. This bill is handed over to the assessee along with the new annual valuation (rate card) after completion of the hearing. The supplementary bill was never updated in the manual system and the assessee had great difficulty in getting his records cleared.

- By automating the full cycle of the hearing system through the use of an online integrated information system, the process is reduced to a few hours, incorporating the following activities

i) generation of hearing notice on the proposed annual valuation

ii) generation of a computerised rate card after the rate is confirmed

iii) handing over the rate card to the assessee

iv) generation of fresh/supplementary bill

v) immediate payment by the assessee at the receiving counter

vi) online reconciliation of the fresh/supplementary bill demand

vii) simultaneous updating of the tax register and all related records.

The automation of the hearing system has greatly increased the assessee's confidence. It has also saved time and money. Calcutta Municipal Corporation is now able to complete the backlog of bill payments and also maintain the general revaluation cycle.

\section{Property records}

Under the Calcutta Municipal Corporation Act, maintaining property records is one of the statutory functions of the organisation. Mutation is the process by which the name of the property owner is changed when ownership of a property is transferred. The Calcutta Municipal Corporation keeps a record of these changes and ensures that the change is reflected on the assessee's consolidated tax bill. Under the old manual system, effecting this change in records was a cumbersome procedure that was inconvenient for the assessee.

Developing integrated software, where the mutation is classified under various heads, and business rules are provided in a logical information database, has resulted in the registration process being a short single-window process (simple mutation).

A variant of mutation is Suo-Moto, a mutation process initiated by the Corporation to bring a new building into the tax net quickly. This process has resulted in a significant increase in revenue for Calcutta Municipal 
Corporation, and there are plans to attach the Building Department's 'Issue of completion certificate' process, which is the new building sanction authority.

The taxpayer has benefited from computerisation of property records in several ways. Payments can be made across the counter at any of the 14 counters located in the city. Even if the assessee does not receive prior payment notice, he/she can approach a payment counter with his/her assessee number or residential address and the computer will provide the information on the exact amount due. Calcutta Municipal Corporation staff have also gained. The replacement of the obsolete cash register system with the computerised system has relieved staff of the drudgery of work, freeing up time to devote to their other activities. It has also led to a reduction in overtime and better utilisation of staff.

Table 10.1 shows the increase in revenues over the period 1993-2001. During this period, as a result of automation, the realisation figures increased substantially-from around 45 per cent in 1993-94 to about 65 per cent in 1999-2000, thus lowering the gap between dues and recoveries.

\section{Challenges faced}

Due to lack of automation in this function, Calcutta Municipal Corporation had not been able to monitor tax collection or mutation proceedings. Manual procedures propagated currupt practices, resulting in large monetary losses for the Corporation and harassment of taxpayers at the hands of the Corporation's clerks.

In carrying out its activities under this function, Calcutta Municipal Corporation faced several challenges.

- The manual system was highly personnel-dependent. Knowledge was concentrated among a small group of employees who had a lot of power. In addition, due to the

\section{Table 10.1 Annual demand (Rs. Crores)}

\begin{tabular}{rrrrrrr}
\hline & Calcutta & Tollygunge & Jadavpur & S.S. Unit & G.R. Unit & Total \\
$1993-94$ & 57.93 & 5.27 & 0.72 & 0.84 & 0.64 & 65.4 \\
$1994-95$ & 62.68 & 5.26 & 0.94 & 1.08 & 0.76 & 70.72 \\
$1995-96$ & 68.16 & 6.08 & 1.24 & 1.24 & 0.8 & 77.52 \\
$1996-97$ & 80.08 & 6.64 & 1.44 & 1.58 & 0.8 & 90.54 \\
$1997-98$ & 88.4 & 7.2 & 1.68 & 1.84 & 0.84 & 99.96 \\
$1998-99$ & 99.99 & 7.6 & 1.91 & 2.29 & 0.88 & 112.67 \\
$1999-00$ & 107.71 & 8.29 & 2.22 & 3.22 & 0.81 & 122.25 \\
$2000-01$ & 125.00 & 9.28 & 2.70 & 4.22 & 0.85 & 142.05 \\
\hline
\end{tabular}


system of lateral transfers, it was difficult to retain this knowledge across departments. Further, in the absence of a centralised repository, there were no standards, and business rules varied widely across the wards. In effect, the small group of employees took advantage of this state of affairs and indulged in corrupt practices. There was the case of an employee whose services had to be extended for 12 years simply because he could not be replaced.

- Calcutta Municipal Corporation must obtain the correct valuation that is to be billed for a financial year. Generally, this figure is revised once every six years (general revaluation) or in any instance when the value of the property changes dramatically, for example through Mutation, addition of a new area, alteration or amalgamation of property (intermediate revaluation).

- Maintaining the correct name of the owner. The name printed on the tax bill is of paramount importance as the bill is considered an authentic document for proof of ownership.

- Maintaining the mailing address to ensure that the bill is served correctly and remains authentic evidence of the property premises.

When the new municipal commissioner took charge at Calcutta Municipal Corporation, this was the first area to become computerised. This activity is now fully computerised and maintained in an online database.

\section{Cost and time implication of automation}

It took roughly two years to automate the system. Investment expenditure was about Rs 1.50 crores for hardware and software (for the headquarters, treasury and suburban centres) and another Rs 1.00 crore for associated infrastructure (buildings, electrical cabling, air conditioning, and so on).

\section{Case 2 Expenditure management}

\section{The need for automation}

When the new municipal commissioner took charge, Calcutta Municipal Corporation's accounting records were hopelessly behind schedule-some accounts were in seven years arrears. The manual system was not efficient in tracking the enormous volume of data and transactions generated daily. Accordingly, the budgeting was based on the system of estimated values of allocations and expenditures, and there was no method of collecting information on actual expenditures incurred under different accounting heads during the year. Further, while the accounting period was supposed 
to close at the end of March, payments to external parties continued to be made as late as September or October of the next financial year. One of the major concerns was that it was impossible to track expenses vis-à-vis the budgetary allocations of various departments. Hence, many expenses were booked more than once against the same order. This was not only due to oversight on the part of the Corporation's staff, but also due to devious methods adopted by contractors in collusion with some officials in the Corporation.

\section{Introducing automation}

One of the foremost goals of the municipal commissioners was to fix the accounting system, and establish a system of financial discipline. This involved introducing budgetary control, introducing a system of checks and balances, as well as making the accounting system accurate and up-todate. Now the processing of bills ceases around 10 March each year in order to ensure accounts are finalised by the end of the month.

Expenditure management has been improved by creating budget heads, which are maintained on the system. All expenses are booked against work order numbers generated by the system and the total expense against any head of account in a financial year is fixed. The cash book and the journal have been automated. The list of vendors is also maintained in the system, preventing favouritism towards select vendors. An inventory of the Corporation's assets has been published for the first time in many years.

\section{Challenges faced}

To overcome resistance to the introduction of IT, the system was introduced progressively and focused initially on the critical applications. Enormous effort was required to bring about this financial discipline among employees. In effect, close monitoring of expenditures became possible and, for the first time, actual expenditure statements for the previous year began to be recorded in budget statements.

\section{Cost and time implication of automation}

It took about two years to automate the system and involved an investment of about Rs 70 Lakhs in hardware and software.

\section{Case 3 Solid waste management}

\section{The need for automation}

Previously, the city's garbage collection system was not only inefficient but also corrupt. Garbage was irregularly picked up from several areas of the city. In addition, since garbage collectors were paid bonuses based on the 
number of trips made and the amount of garbage collected, they would make false trips and state incorrect tonnage. It was common practice to make false trips, make trips with half-full trucks, or even use the same load of garbage and show multiple trips in the records. While garbage used to pile up in the city, records showed remakable diligence amongst the city's garbage collectors, with some trucks making as many as many as 1200 garbage disposal trips per day. This resulted in excess expenditure on petrol bills and wages. Further, the garbage dump was controlled by a mafia group who encouraged this malpractice.

\section{Introducing automation}

The municipal commissioner sought to improve this state of affairs. During a tour to Chicago in 1995, he learned how IT had been deployed in Chicago to correct these types of failures in garbage management. He decided to adopt a variation of the Chicago practice in Calcutta.

As the first stage of IT implementation, a Foxpro-based rudimentary system was introduced in the garbage dump at Dhapa. This system would note the garbage trucks' time of entry to, and exit from, the dump. This simple measure streamlined the system significantly. False trips by particular trucks were reduced and the average number of trips fell to roughly 700 per day.

Three other initiatives were also introduced. Despite stiff opposition, private garbage collection was introduced to complement the CMC's system. This was based on the fact that, even if the CMC's own system of garbage collection and disposal was fully operational, it could only ensure disposal of 60 per cent of the total garbage generated daily in the city. Second, the incentive system was rationalised. The tonnage of garbage dumped was used as the measure of productivity rather than the number of trips made. This rapidly reduced the number of trips made. Finally, a weighbridge mechanism was introduced so that the weight of each truck's contents could be easily determined, and payments made on that basis. Thus, measurement of the weight and number of trips made by each vehicle has been automated, reducing the scope for falsification of data. This has also resulted in more efficient garbage removal, a cleaner environment, and greater resident satisfaction. Currently, $\mathrm{CMC}$ and private contractors' vehicles make an average number of 500 trips per day, and the trucks always carry a full load of garbage.

\section{Challenges faced}

It initially appeared that the workers at the garbage dump-who were controlled by the mafia-would not allow the new system to be implemented. Garbage was dumped next to the computer centre, and the 
road leading to the dumping site was deliberately lined with lorries to prevent smooth movement of the garbage trucks operated by private contractors. In addition, the electric power lines did not extend all the way to the rather remote garbage dump, which meant there was no way of powering the new system. Initially, the system was implemented using generators. Senior officials of Calcutta Municipal Corporation had to keep a vigil to ensure that the system began without any hitches.

\section{Cost and time implication of automation}

The system took about one year to automate, and involved an investment of about Rs 30 Lakhs (computers and weighbridge), Rs 50 Lakhs (building, electrical cabling and air conditioning) and roughly Rs 2 crores on road development within the dumping yard.

\section{Incorporating Information Technology-how did it happen?}

Introduction of IT was based on a three-pronged strategy adopted by the new municipal commissioner. The aims were to

- improve employee morale

- raise revenue

- control expenditures.

\section{Gaining employee confidence}

A series of free and frank dialogues with various employees' unions was initiated to win the employees over to the computer program. The dialogues centred around the following points.

- The process of computerisation would not pose any immediate threat to the staff as far as their tenure in Calcutta Municipal Corporation was concerned.

- Automation did not necessarily imply diminished job opportunities.

- Computerisation was being introduced to aid their efficiency and effectiveness.

- Manual compilation and tabulation processing of these data was fraught with risk. Disciplinary proceedings were initiated against some staff for mishandling of data.

- The entitlement of staff in terms of disbursements of Provident Fund could not be properly ascertained due to the volume of transactions. As a result, many staff suffered.

- It was impossible to meet the growing establishment costs, particularly the ever-increasing wage bills due to the huge 
number of Calcutta Municipal Corporation staff, if the resource base was not augmented. It was not possible to bring more citizens into the tax-net through traditional manual methods. Moreover, raising huge numbers of bills manually was not possible. The necessary decentralisation and mechanisation was only possible through computerisation.

- If Calcutta Municipal Corporation staff did not become acquainted with modern technology they would become redundant as the massive changes in IT occurred all over the world.

- Institutional pride amongst staff is the essence of any organisation. Only through such pride could the negative image of Calcutta Municipal Corporation be countered, and that was only possible if computerisation - devoid of any discretion or favouritism-could be introduced, particularly in the public service oriented departments.

- Calcutta Municipal Corporation has a big role to play in making Calcutta environmentally-friendly, citizen-friendly and investor-friendly. Only through that process can more job opportunities be created in the city. Therefore, the staff of the Corporation have a big responsibility in ensuring a better future for Calcutta.

Dialogue with employees' unions can only yield results when it is accompanied by concrete action. Several steps were taken to restore employee confidence in the organisation by making it clear that the authority meant business and had no intention of replacing manpower with machines.

A special training institute was set up to train all Corporation staff in the new system. Training programs ranged from orientation courses to threemonth and one-year courses, and were successful in making the staff extremely computer-literate. A new environment, favourable to computerisation, was gradually established.

Calcutta Municipal Corporation has 18 treasury counters. They used to handle cash and calculate the transactions using cash register machines. At the end of the financial year, and on many other occasions, staff were required to work until late evening counting cash and processing transactions. It was felt that computers should be introduced at the treasury counters to make the work more accurate, smooth and effective. Where before there were heated arguments between Corporation staff and ratepayers regarding delays in the collection of money, and incorrect compilations and tabulations, the introduction of computers in Treasury improved customer-staff relations. A sense of institutional pride was also established among CMC staff. 
There were other benefits from computerisation.

- Staff were concerned that the compilation of their contributions to Provident Fund was incorrect. The accounts of Provident Fund had been in arrears for a long time. As a result, staff were unsure about their entitlements. The introduction of computers in Provident Fund dispelled staff fears.

- It was very difficult to prepare cash journals involving large amounts of bill and cheque transactions in the Finance and Accounts Deptartment. Even with their best efforts, they could not prepare proper accounts on time. At one point, CMC accounts were more than seven years in arrears. Hence, Corporation staff in the Finance and Accounts Department welcomed computerisation.

- Previously, the process of promotion and transfer of staff was inefficient. Manual preparation of gradation lists and issuance of promotion orders through traditional methods took a long time. Corporation staff in the Personnel Department welcomed the introduction of computerisation to ease this problem.

- With the gradual introduction of production incentives to Corporation staff, staff confidence grew. But preparation of correct incentive bills for the huge number of staff was a major problem. Moreover, the clerical staff who were to prepare the incentive bills were reluctant to do so because they were not the beneficiaries of the incentive program. Therefore, the field staff welcomed the computer program for making the preparation and disbursement of incentive bills smoother and more accurate.

- Printing and electronic media was effectively utilised in gaining public confidence in the Corporation's computerisation program. The benefits that accrued to citizens through the computerisation process were highly publicised. The response from the citizens was so encouraging that both the management and the employees' unions proceeded to implement further computerisation in other departments.

\section{Gaining political support}

Calcutta Municipal Corporation is run by a democratically elected Mayorin-Council system. Judging the public mood and assessing the benefits of computerisation both for revenue collection and expenditure management, the members of the Mayor-in-Council became ardent suporters of computerisation. Some of the members of the Mayor-in-Council thought that computerisation was a panacea for all the evils of administration. 
Being elected representatives, the members of the Mayor-in-Council have many responsibilities to the citizens. Therefore, they were very concerned about the image of the organisation. They wanted to introduce transparency and accountability and thought that computerisation would achieve this.

Because Calcutta Municipal Corporation is a vast organisation, the directives of the management were not always strictly adhered to by its staff. This could be attributed primarily to the lack of proper supervision by middle management, and also to the lack of knowledge in interpreting various circulars issued by the management. Close scrutiny of the transactions in various departments revealed that actual field operations differed within various sections of the same department, not to mention other departments, and contravened both the objectives and the spirit of the Calcutta Municipal Corporation Act. Essentially, a huge gap existed between the statute and rules and what was actually practiced. The Mayorin-Council believed that the only way to bridge the gap was to analyse the business rules through development of proper computer packages, and enforce them with uniform implementation. They thought that introduction of proper business logic and uniform application of various packages would enable Calcutta Municipal Corporation to create greater transparency. For example, raising supplementary bills on account of property tax and providing facilities in terms of rebates and instalments in a uniform manner was welcomed by taxpayers and also helped the CMC raise more revenue.

\section{Streamlining operations}

The municipal commissioner felt that for any new institutional strengthening initiative to succeed it was vital that the endemic problems of generating resources for the cash-starved Corporation, controlling avoidable expenditure, and gaining public confidence needed to proceed in parallel. Accordingly, the specific areas in which IT was to be introduced were chosen with care. Targets and objectives of the IT Implementation Program were defined in a phased manner. The main hindrances were ambiguities associated with the business rules definition, information on data availability, and assigning responsibilities to ensure the process worked smoothly.

\section{Developing a vision}

Keeping these constraints in mind, the following objectives were set

- incorporate transparency into the system

- reduce process completion time

- eliminate manual procedures 
- add control and audit trails to the system

- simplify the business process for faster decisions

- increase revenue

- reduce multiple data capture points (reduce data redundancy)

- ensure better management control

- enforce standards (like usage of pre-printed stationery).

To achieve these objectives, a high-level task force was set up under the direct supervision of the municipal commissioner. Use of the latest reliable hardware and software was encouraged and high quality networking solutions were adopted. Within three years, a huge computing resource was established.

\section{Implementing the action plan}

As expected, the implementation of the IT system encountered strong resistance from many quarters. One of the main sources of resistance was employees. This was manifested in the form of non-cooperation or slow response, but commitment of the management team and the strong support of the municipal commissioner have gone a long way to solving this problem.

Initially, the new system was implemented through contract staff. This was slowly changed, and the system is currently run by the CMC's own employees. In order to train its own staff to use computers, the $\mathrm{CMC}$ has started a computer-training institute. Education and computer awareness among employees has had a positive effect on the management's pro-IT stand. Fresh recruitment of IT-oriented staff and IT training of staff in key managerial positions has also helped.

\section{Lessons learned and recommendations}

Computerisation of CMC processes is not simply a matter transferring of the data in paper documents to electronic media. The process has sought to introduce logic into the system. This logic is based on fixed parameters. At the Corporation, much work used to be done without any logic or welldefined parameters. Therefore, under computerisation, establishing the parameters with uniform logic was the greatest challenge. Computerisation thus necessitated the initiation of a series of administrative and financial reforms.

The management felt that the reforms could be undertaken alongside computerisation. The informal practices originally followed by CMC staff for their personal aggrandisement gave way to stratified uniform business rules. Transparency has been the key parameter in the administrative reforms, and there has been a major transformation in the work attitude of the staff 
and the attitude of citizens and other external entities, such as suppliers and contractors, towards the Corporation as a result.

The implementation of IT has eliminated many unscrupulous aspects of the system. The uniform policy prescription, coupled with the attitudinal change of the top and the middle management, gave a new dimension to the dealings between the Corporation and its clients. It enabled the Corporation to augment its resources and establish a new image.

Upon its deployment, IT became an important tool for better governance and institutional strengthening in the hands of the Corporation's decisionmakers. An analysis of how the IT intervention brought about institutional change delivers certain interesting insights. Reforms and improvements can be initiated in a system irrespective of the extent of its existing malaise. It is necessary to draw up a strategic plan and implementation program, secure top management commitment and build stakeholder buy-in. In addition, IT can be an effective mechanism to arrest institutional failure and provide good governance in public sector/ government organisations interfacing with citizens. Finally, implementation of IT to arrest institutional failure is most successful when adopted in a progressive manner, with sufficient prior work on planning, pilot implementation, organisational development and discipline enforcement. At the Corporation, the process was implemented under a five-stage model. Stage 1-set strategic agenda. The success of deploying IT in government organisations such as municipal corporations is dependent on a sponsor setting a strategic agenda for implementing IT and showing commitment to a program of institutional change. In the case of the CMC, it was the organisation's municipal commissioner who, upon assuming responsibility, ensured that he understood the benefits of IT in establishing better governance in critical municipal services and took an active interest in the project, reviewing its progress at regular intervals.

Stage 2-launch pilot project. Rather than deploying IT all at once across the entire organisation, it is preferable to launch the IT project on a pilot basis. At the Corporation, IT was initially introduced in one critical areaproperty taxation and assessment.

Stage 3-reconfirm strategic agenda. At this stage, based on the successful results from the initial pilot implementation, the sponsor reconfirms the priorities and benefits of IT implementation and pledges support for it. The scope of the pilot project is then widened. In CMC, this stage included reaffirmation of the Commissioner's commitment to the IT initiative and inclusion of a number of other critical functions in the implementation program. These functions were-budgets and expenditure and solid waste management. 
Stage 4-project roll-out. By this stage the results of computerisation are evident. At the Corporation, this stage involved parallel implementation of the IT program in the three chosen areas and increased coverage of the organisation's employees. Thus, from its beginnings at the headquarters, the program was extended to the Corporation's eighteen nodal receipt centres and the waste dump-yard at Dhapa.

Stage 5-drive benefits and change. Finally, it is imperative for the organisation to distribute the benefits throughout the organisation and reaffirm support for an organisation-wide process of IT-enabled change. The Corporation is currently undergoing such change and has ambitious plans to expand its IT base in its core business operations. 